\title{
ע)
}

\section{A URGÊNCIA DA POÉTICA}

Joedy Luciana Barros Marins Bamonte (DARG/FAAC/UNESP)

joedy@faac.unesp.br

\begin{abstract}
Resumo
O processo criativo é algo constante, configurado como uma rede de conexões. Em uma tessitura permanente, dados são agregados, gerando novos registros e obras artísticas dentro de uma poética. Transcrevo o desenvolvimento de três séries de trabalhos criadas por mim, envolvendo escolhas, seleções e interpretações inerentes ao continuum criativo. Com amparo na crítica de processo, saliento como esse percurso, em toda sua pessoalidade, delineou-se na necessidade de exteriorizar conflitos pessoais, percepções e elaborações mentais que constituem o ser artista, pesquisadora e docente.
\end{abstract}

Palavras-chave: Processo Criativo. Crítica de Processo. Joedy Marins.

Abstract

The creative process is something constant, configured as a network of connections. In a permanent texture, data is aggregated, creating new records and artistic works interpreted in a poetic. Transcribe the development of three series of works created by me, involving choices, selections and interpretations inherent to the creative continuum. Supported in the process of criticism, I emphasize how this route, in all its personhood, has been delineated in the need to externalize personal conflicts, perceptions and mental elaborations that constitute the human as artist, researcher and professor.

Keywords: Creative Process. Process of Criticismo. Joedy Marins.

No processo criativo, as escolhas constituem tessituras em potencial, conexões em rede. Nelas, ações aparentemente externas são identificadas com espaços da intimidade, à medida que a poética do artista constrói proximidades entre referências que lhe apresentem familiaridades. Dentro desse contexto, transcrevo vivências pessoais, reflexões à luz de Cecília Almeida Salles, Maurice Merleau-Ponty e Gaston Bachelard, enfatizando a crítica de processo como linha teórica. 


\section{《I}

Gradativamente, minhas pesquisas se debruçam mais na problemática existente entre os espaços do ateliê, universidade, galeria, publicações. Refletir, compreender, trazer respostas à necessidade de produzir, ensinar e continuar a aprender é um desafio instigante e fascinante. Há momentos de alternância entre atividades diferentes como a docência, a pesquisa e a produção artística que parecem pausas pontuais, mas que objetivam as mesmas respostas. Nesses trânsitos, a criação estabelece as conexões, flexibilizando fronteiras de resistências, que muitas vezes se mostram inexistentes. Entretanto, elas discernem entre o que ainda está no plano das ideias do que está para ser materializado, entre o que é desnecessário e o que é imprescindível.

\section{Fluxo poético}

Sentada, lendo Merleau-Ponty somente sinto aguçar, inflamar o desejo de produzir. O fluxo criativo parece pulsar entre as constantes produções acadêmicas, sinalizando a urgência de interromper atividades que se tornam automáticas. As fronteiras, que antes pareciam sutis, evidenciam-se favorecendo a materialização em suportes e operações distintos. Como contrações, o processo sinaliza seu formato, seu veículo, seu suporte, para que a criação nasça. O momento da "modelagem" da obra chega exigindo manipulações, construções e ações específicas em sua materialização, a escolha do veículo através do qual a ideia será comunicada.

o cérebro, dividido constantemente em atividades alternadas e complementares, parece tornar-se mais seletivo. Há uma constância nos trabalhos cotidianos e corriqueiros, entretanto, a ânsia pela imersão é latente, tornando-se emergencial ao ser protelada. A procrastinação para criar parece fazer do trabalho algo insalubre. O tempo necessita de uma nova configuração, um novo ritmo, onde operações mentais 


\section{《)}

farão as conexões entre insights aproximando documentos de processo e trazendo a fisicalidade da obra artística.

A pausa (que evidencia o que chamo de fronteiras) deixa de ser sutil e passa a ser interpretada como o momento de direcionamento específico para a interpretação. o olhar para o mundo está inflamado, precisa ser codificado. Essa fase ocorre quando a sequência de atividades burocráticas da universidade, que se impõe lentamente sobre o processo criativo, precisa ser interrompida. Há que se refletir sobre o que vem sendo automático. O espaço do ateliê chama ao isolamento, ao silêncio, ao que está represado. O momento da criação se torna urgente, o processo de materialização das ideias, experimentação de materiais a partir de anotações, registros, fotos acumuladas, a absorção do que Merleau-Ponty menciona:

o mundo é não aquilo que eu penso, mas aquilo que eu vivo; eu estou aberto ao mundo, comunico-me indubitavelmente com ele, mas não o possuo, ele é inesgotável." (1999, p.14)

A leitura do mundo manifesta-se nos espaços da intimidade, o que absorvi da realidade, de minhas observações e de mim mesma, a partir de mim, necessita ser "traduzido". O que é sentido, percebido não pode ser contido por ser contrário à própria dinâmica criativa da existência, que precisa ser realizada, expressa. A negação dessa dinâmica gera estagnação, como uma patologia que se alimenta do acúmulo de percepções que não pode ser mais contido, precisando ser compartilhado dentro de um processo de comunicação e valoração pessoal. Em uma relação recíproca, o valor dessas percepções está em compartilhar, intensificar e sinalizar os sentidos em ação, em intensa atividade. São sinais de vida abertos à interpretação, em um fluxo contínuo que se autoalimenta alternando entre criar e compartilhar. 


\section{\.}

Para proceder a leitura e maior compreensão disso, especifico processos dispostos em conexões pessoais referentes ao período entre 2013 e 2015. Eles estabelecem conexões com outros, dentro do que Cecília Almeida Salles denomina redes de criação, um sistema em construção, próximo às interações feitas pelos ecologistas:

"(...) estamos preocupados com as interações, tanto
internas como externas aos processos, responsáveis pela
construção de obras, pois são sistemas abertos que
interagem também com o meio ambiente." $(2003$, p.24)

Os processos vêm de encontro a questionamentos já iniciados em minhas pesquisas, justificando a aceitação da proposta feita pelo artista plástico Fernando Augusto para desenvolvimento de desenhos diários durante o ano de 2015, o que intitulou "Um ano desenhado". Simultaneamente aos registros do projeto, outros também surgiram, em um diálogo que trouxe conteúdos anteriores, inclusive.

Menciono a atividade como escolha feita por estar 176 diretamente relacionada ao meu impulso criativo e ao que me interessa atualmente. Enriquecedora para a produção de meus registros, considero-a como facilitadora, método que pontuou meu percurso, constituindo os próprios documentos de processo, impulsionados e impulsionando uma dinâmica dialógica com a universidade, ora alternada, ora exclusivista. Sem isso a docência e a pesquisa não poderiam ser alimentadas.

\section{Um ano desenhado e outros registros}

Ao final de 2014, o artista plástico, curador e professor Dr. Fernando Augusto dos Santos fez uma convocatória em seu perfil no Facebook para o Projeto "Um ano desenhado", no qual os participantes produziriam desenhos diários. Este desafio foi aceito por mim.

Durante o ano de 2015 meus sketchbooks tornaram-se preenchidos mais por desenhos do que por textos verbais. Os 


\section{《)}

registros contemplaram traços, observações mais atentas do cotidiano, exercícios constantes que adotavam quaisquer cenas como pretextos para o ato de desenhar.

o início de "meu ano desenhado" ocorreu em meio à mudança de residência, envolta em caixas de papelão, roupas sobrepostas, acúmulo de objetos e móveis, empacotamentos. Parar diante dessas cenas e desenhar, em si, já era um desafio e tanto, entretanto, tornou-se um fio condutor para descobrir "paisagens", caminhos que comumente estão à disposição. A desmontagem, o bagunçado, o entulhado se apresentaram aguçando o desafio, as desconstruções, o deslizar no papel ao descobrir composições novas.

o início do ano também foi marcado por um período de luto, de despedida. Conflitos pessoais despertos pela perda de minha avó materna caracterizaram a intensidade das vivências durante meses, nos quais percebia delicadezas que marcaram o convívio pessoal, já manifesto em trabalhos como "Legado", inclusive, uma colcha de retalhos que confeccionei com ela, sobre a qual inseri objetos do quotidiano da mulher, uma criação artística que constituiu o objeto de estudo de minha tese de doutorado, em 2004.

Em um período extremamente reflexivo e profundo de imersão pessoal, pude perceber, dia após dia, a apropriação da palavra legado, como algo que não se dissocia do indivíduo, de sua identidade, ricamente intrincado e tecido em quem eu sou, características herdadas, mas tramadas em um tamanho grau de complexidade que garante, ao mesmo tempo, o pertencimento à minha ascendência e a distinção e unicidade de minha identidade.

A entrega aos desenhos permitiu um conhecimento maior de minha extensão, como o cantor conhece melhor a tessitura de sua voz, dos agudos aos graves, como o bailarino tem um maior domínio da elasticidade de seu corpo e potência de sua 


\section{R| Revrsta \\ A APOTHEKE}

musculatura, como o ator trabalha a expressão de sua voz, corpo, emoções.

A cada desenho houve escolhas entre a proximidade realista, o peso do material sobre o papel, a escolha do traço mais esfumado ou riscado, mais rápido ou minucioso, realista ou abstrato, em caminhos que se confirmavam, surpreendiam-me, desafiavam e realizavam-me ao encontro de anseios e respostas.

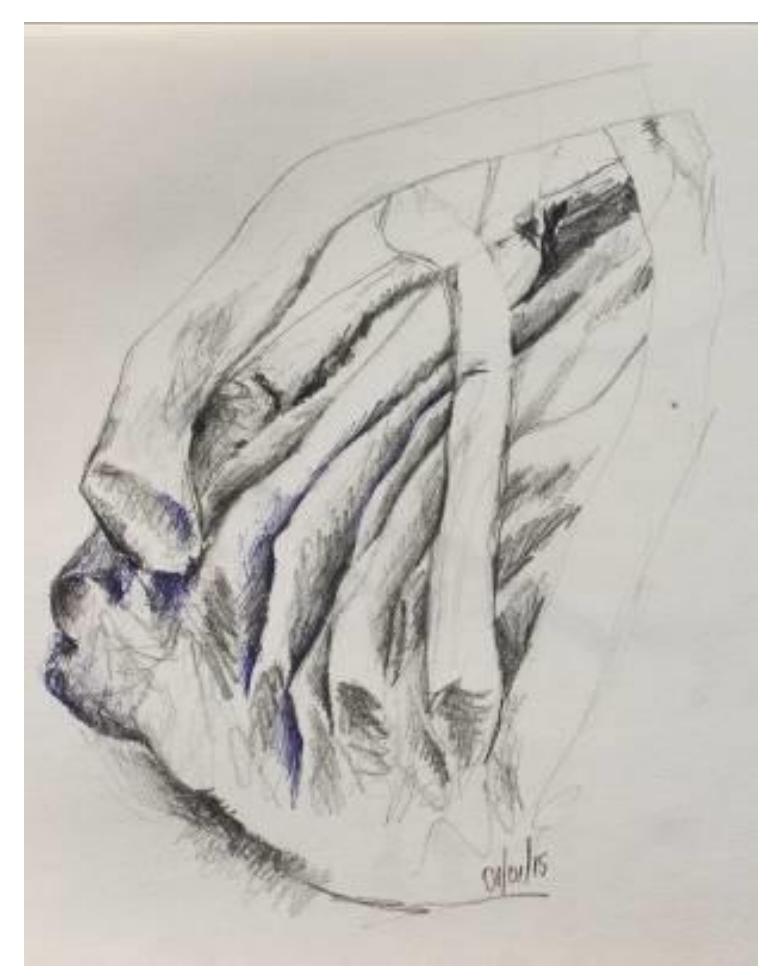

Figura 1: Primeiro desenho da série "Um ano desenhado", Joedy Marins, 2015. (Acervo pessoal) 


\section{REVISTA
APOTHEKE}

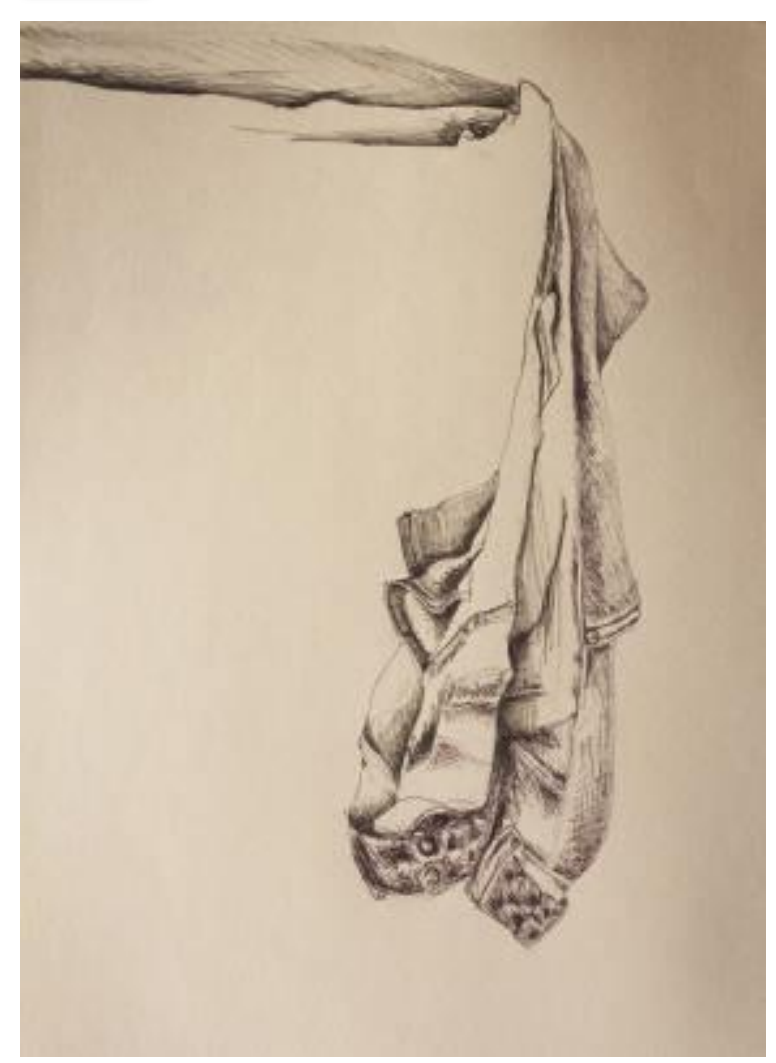

Figura 2: Desenho da série "Um ano desenhado", Joedy Marins, 2015. (Acervo pessoal)

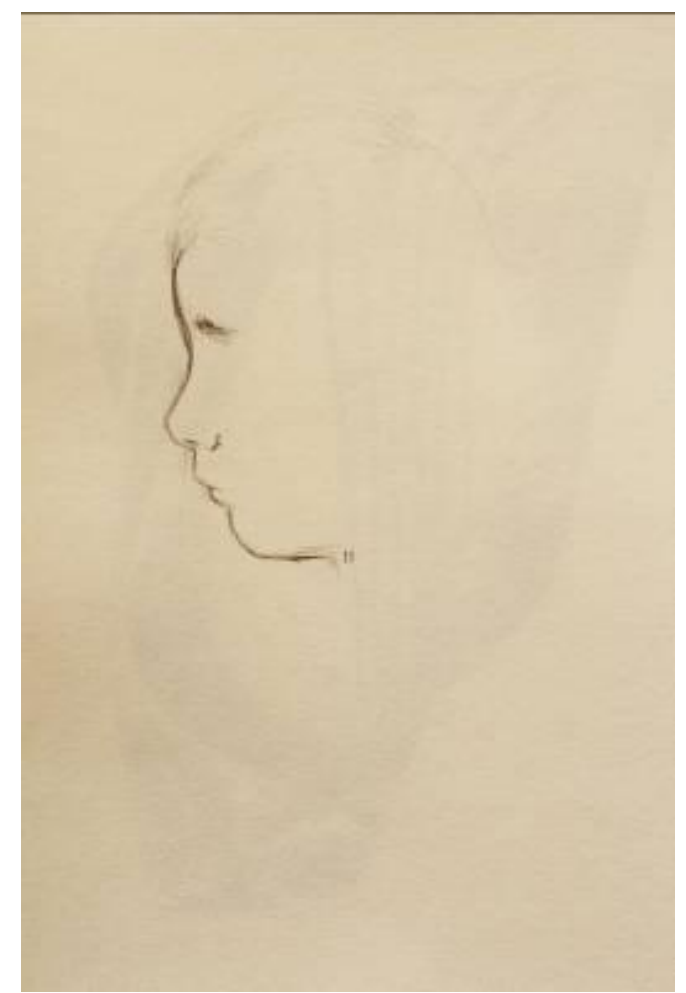

Figura 3: Desenho da série "Um ano desenhado", Joedy Marins, 2015. (Acervo pessoal) 


\section{REVISTA
APOTHEKE}

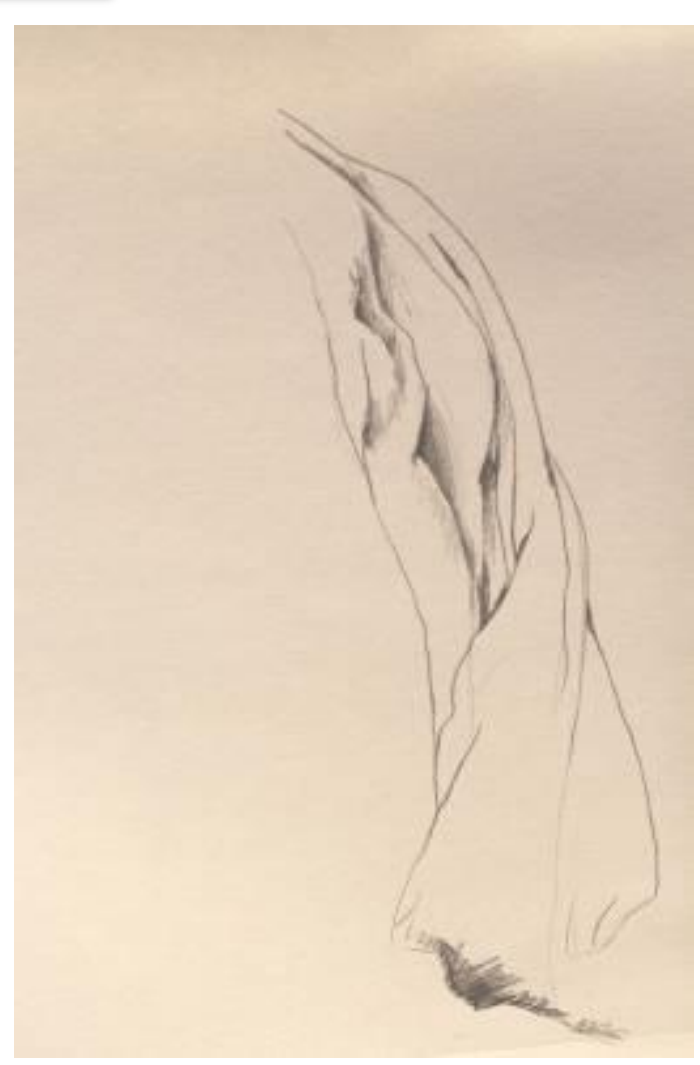

Figura 4: Desenho da série "Um ano desenhado", Joedy Marins, 2015. (Acervo pessoal)

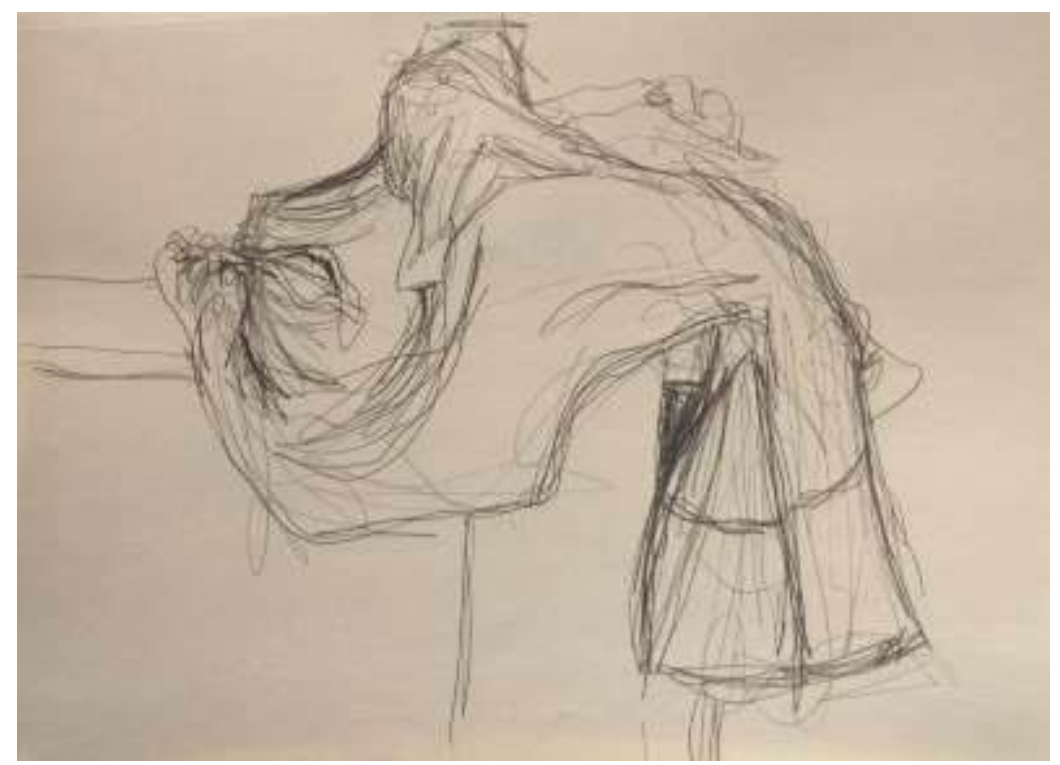

Figura 5: Desenho da série "Um ano desenhado", Joedy Marins, 2015. (Acervo pessoal)

Ao findar 0 ano de 2015, pude visualizar uma amostra intensa e enriquecedora de minhas vivências enquanto artista. 


\section{VI}

Embora não tenha conseguido elaborar trabalhos diários, houve um envolvimento profundo com meu traço e forma de utilizar os recursos do desenho, o que ele é para mim, o que significa dentro de minha poética. Houve dias em que o registro gráfico não ocorreu, dando lugar ao registro fotográfico, alternados com outros em que um forte impulso gerava dezenas de desenhos, em materiais diversos.

Em todos os registros, a busca pela intimidade se manifestava, a partir de marcas do lar, presenças traduzidas em desenhos de observação e criação, figurativos e abstratos. Encontro-me em todos eles e aprendo um pouco mais de mim. São registros de delicadezas, sutilezas, tolerância e persistência, generosidade com o que sei, com o que aprendo. São resultantes de momentos de concentração, silêncio e, como diria Louise Bourgeois, garantia de saúde mental.

As fotografias apresentam características investigadas nos desenhos. Dobras, volumes, linhas surgem nas imagens em diálogo com os registros dos cadernos, sugerindo abstrações e apresentando focos de interesse comuns. Nesses momentos, o olhar continua a buscar por meio da câmera a observação já iniciada para elaboração dos registros gráficos. Os enquadramentos são muito próximos, estendem-se mutuamente de uma ferramenta a outra, confirmando objetos de estudos procurados no processo criativo. A poética transita entre o desenho da luz, do olhar e da mão. 


\section{REVISTA
APOTHEKE}

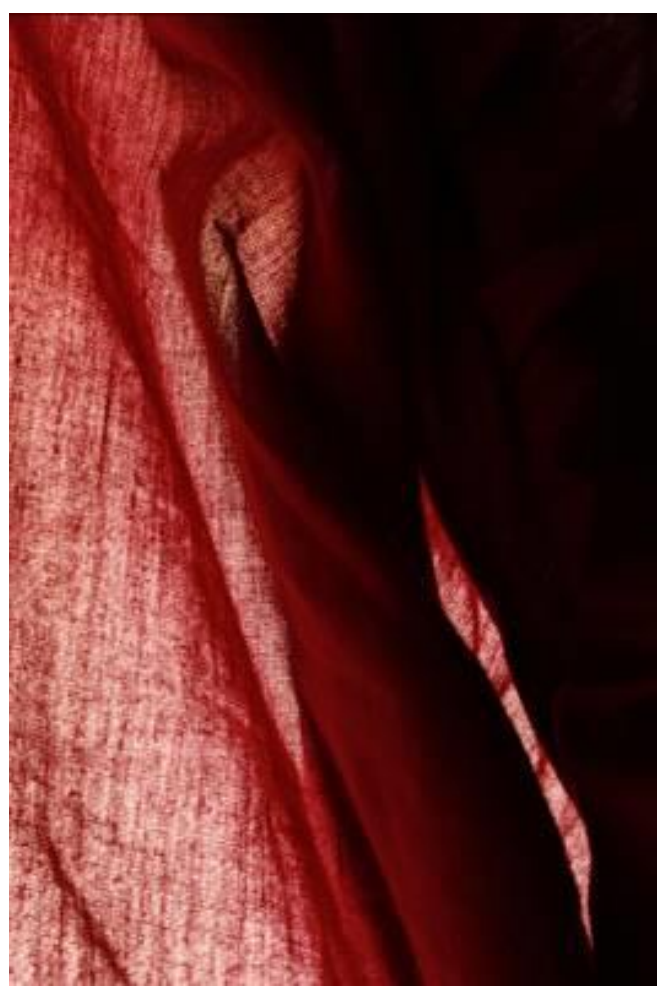

Figura 6: Sem título, Fotografia, Joedy Marins, 2015. (Acervo pessoal)

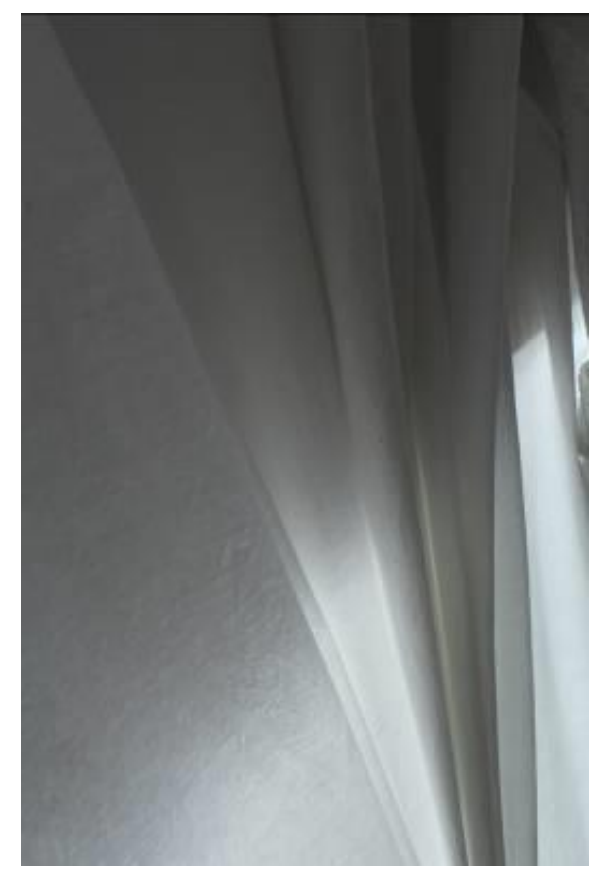

Figura 7: Sem título, Fotografia, Joedy Marins, 2015. (Acervo pessoal)

No trajeto percorrido, há proximidades com trabalhos anteriores, realizações gráficas que também estão nas fotografias. Fotografias que continuam a acontecer 


\section{A $\mid \begin{array}{ll}\text { REVISTA } \\ \text { APOTHEKE }\end{array}$}

paralelamente aos desenhos, como desenhos, sob o mesmo olhar perscrutador. Nesse contexto, menciono a série "Vestígios", de 2013, na qual investigo cenas do cotidiano a partir da intimidade do lar, também com base em Gaston Bachelard. Para melhor abordagem, cito trecho de artigo de minha autoria, de 2014, publicado nos anais do Congresso Poéticas da Criação $(2008)$ :

(...) Em 2013, o espaço da intimidade abordado por Gaston Bachelard direcionou à procura de marcas que diariamente apagamos em nossas casas ao nos organizar, limpar. As fotos nasceram da procura pelas pessoas através das intervenções que fazem em sua moradia e que são apagadas diariamente. Preparar a casa para receber o outro, arrumá-la, é retirar as provas de que passamos por ali, retirar nossa presença, onde somos encontrados. Chamo essa série de "Vestígios" e a produzi buscando as marcas do uso em minha casa, momentos antes de ser limpa, arrumada. (...)

(...) nessas marcas nos encontramos como vestígios de nós mesmos, de humanidade. Sem elas, a casa não tem o cheiro de quem nela habita, de seu jeito, da pessoalidade, não carrega vestígios de vida. A assepsia nos faz impessoais de certo modo. Na "desorganização", encontro quem passou por ali, meus familiares, a mim mesma. São imagens que reconhecem registros, o olhar que capta o "desenho" das marcas. Nesse sentido, a fotografia testemunha novamente 0 registro de um pequeno universo criado, visitado, como faço em minhas obras prontas. Posso ler em "Vestígios", metáforas do rascunho que nasce obra. (BAMONTE, 2014, p.)

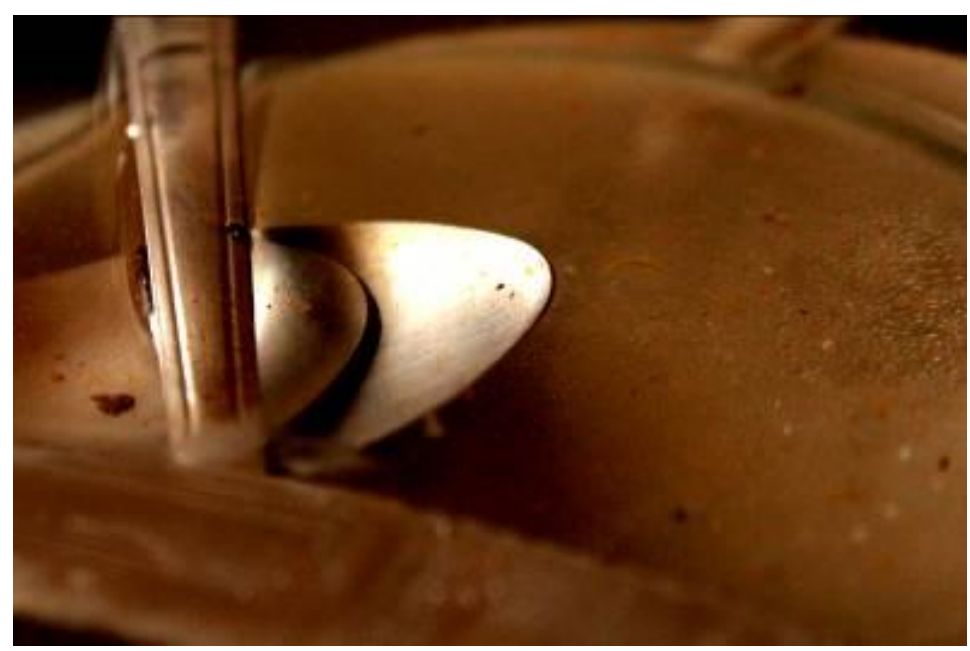

Figura 8: "Vestígios" n 6. Joedy Marins. Fotografia digital. 2013 (Acervo pessoal) 

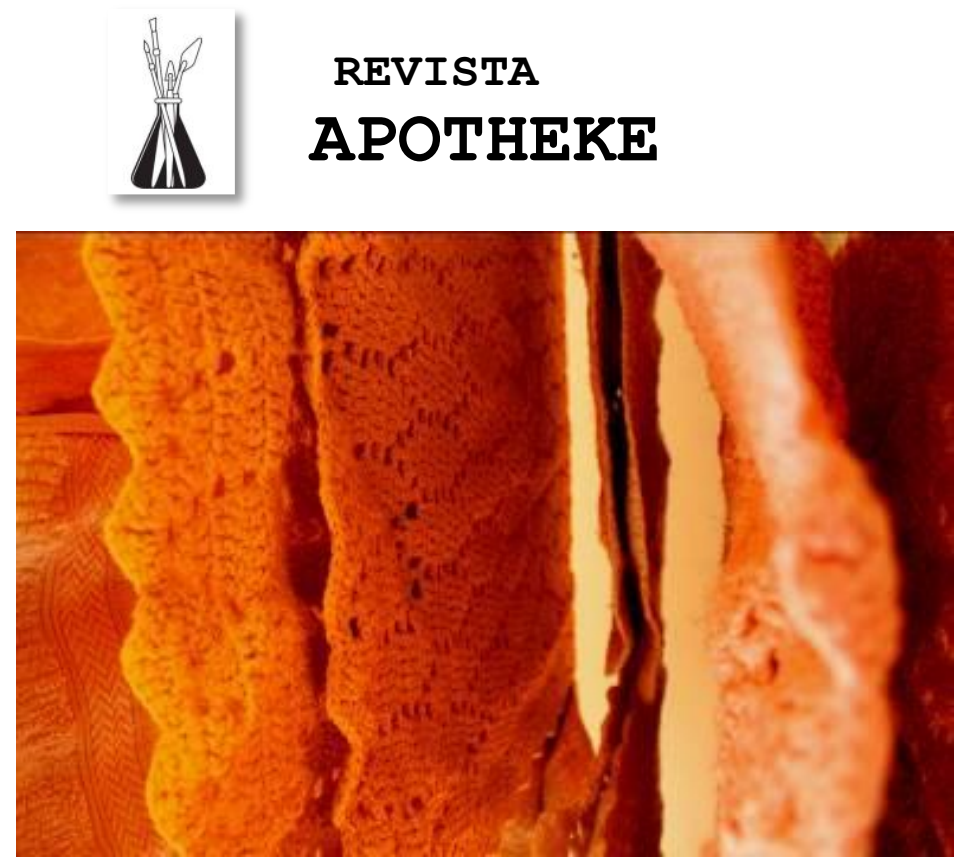

Figura 9: "Vestígios" n 6. Joedy Marins. Fotografia digital. 2013 (Acervo pessoal)

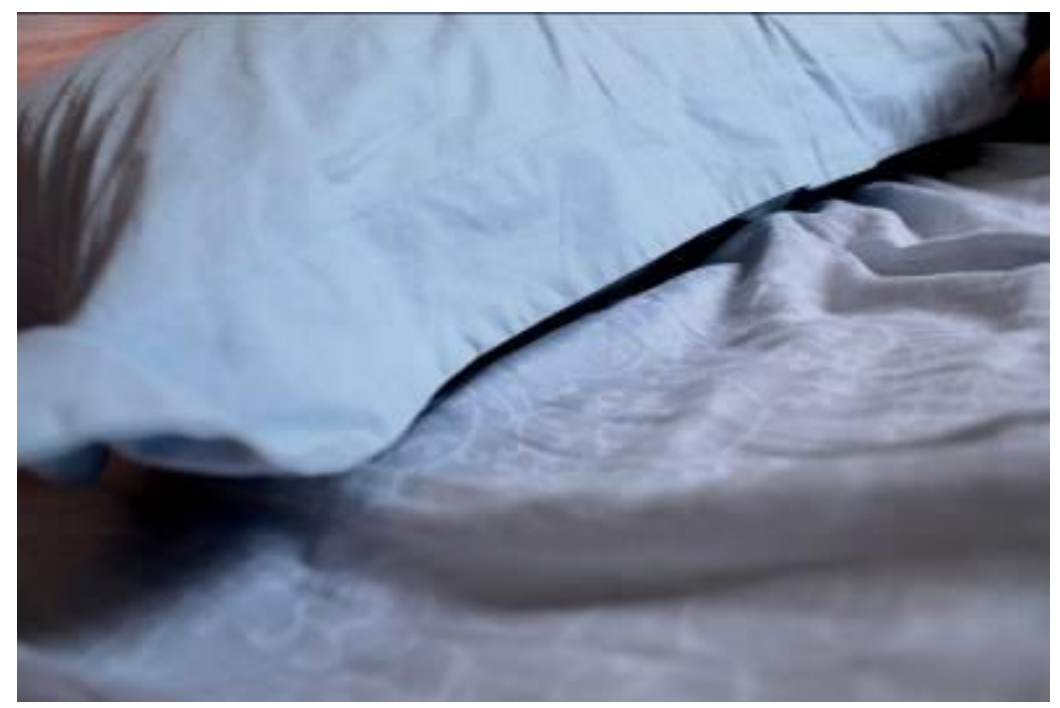

Figura 10: "Vestígios" n 6. Joedy Marins. Fotografia digital. 2013 (Acervo pessoal) 


\begin{abstract}
REVISTA
APOTHEKE

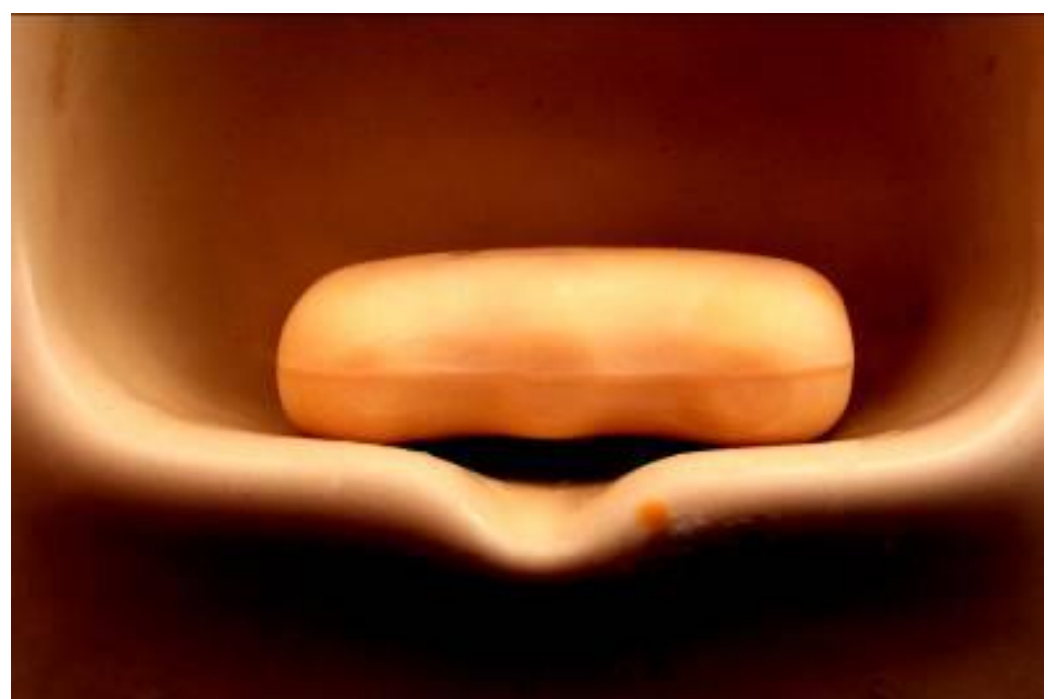

Figura 11: "Vestígios" n 8. Joedy Marins. Fotografia digital. 2013 (Acervo pessoal)

Dentre as três séries mencionadas, faço um recorte de um conjunto de mais de seiscentas imagens. São sinais de procura, de auto-organização e ao compartilhá-los, compartilho também um pouco de mim. Ao identificá-las como pontos em uma rede que está em conexão constante, vejo o quanto ela é infinita e se alimenta a cada ano de vida que tenho. Muitos pontos existem e não foram mencionados. Alguns jamais serão. Talvez não sejam lembrados sequer por mim, mas nem por isso deixam de alimentar a rede. Favorecendo a criação, colaboram com a urgência de renovação da própria vida e ao que virá pela frente.
\end{abstract}

\title{
REFERÊNCIAS BIBLIOGRÁFICAS
}

BACHELARD, Gaston. A poética do espaço. 2ed. São Paulo: Martins Fontes, 2008.

BAMONTE, Joedy. Quando os registros não querem ser rascunhos: a familiaridade com as mídias contemporâneas no processo de criação. Disponível em:

<http://www.4shared.com/web/preview/pdf/5eRdr3UJce?> . Acesso em: 12 de jan. 2016. 


\section{H) Revrsta \\ A APOTHEKE}

MERLEAU-PONTY, Maurice. A fenomenologia da percepção. São Paulo: Martins Fontes, 1999.

SALLES, Cecília A. Redes da criação: construção da obra de arte. Vinhedo: Horizonte, 2003.

Joedy Luciana Marins Barros Bamonte, Artista plástica (Universidade Presbiteriana Mackenzie,1991); Mestre em Comunicação e Poéticas Visuais (UNESP, 1998); Doutora em Ciências da Comunicação/ Comunicação e Estética do Audiovisual (ECA-USP, 2004). Docente (DARG/FAAC-UNESP, 2008- ). Líder do grAVA (2009-). Membro da ANPAP (2011-). 